This is the peer reviewed version of the following article: A Proposal on How the Regulator Should Set Minimum Interest Rate Guarantees in Participating Life Insurance Contracts, which has been published in final form at https://doi.org/10.1111/jori.12036. This article may be used for non-commercial purposes in accordance with Wiley Terms and Conditions for Use of Self-Archived Versions.

\title{
A Proposal on How the Regulator Should Set Minimum Interest Rate Guarantees in Participating Life Insurance Contracts
}

\author{
Hato Schmeiser, Joël Wagner*
}

\begin{abstract}
We consider a contingent claim model framework for participating life insurance contracts and assume a competitive market with minimum solvency requirements as provided by Solvency II. In a first step, the implications of the regulator's imposing a particular interest rate guarantee on the insurer's asset allocation are analyzed in a reference situation. We study the sensitivity of the interaction between the interest rate guarantee and the asset allocation when the risk-free interest rate changes. Particular attention is paid to the current market situation where the guaranteed interest rate is very close to the risk-free interest rate. In a second step, we assess at what level the interest rate guarantee should be set by the regulator in order to maximize policyholders' utility. We show that the results yielded by the proposed concept to derive an optimal value for the interest rate guarantee are very stable for various model parameters.
\end{abstract}

Key words participating life insurance $\cdot$ interest rate guarantee $\cdot$ solvency regulation $\cdot$ risk-neutral valuation · utility measure

\section{Introduction}

A minimum interest rate guarantee and participation in the annual return of the insurance company's asset portfolio are the two core components in traditional endowment contracts most popular in the German-speaking countries. Both elements are offered in so-called participating life insurance contracts and are in general regulated by the insurance supervisory authority. In current contracts offered, minimum interest rate guarantees are based on the savings premium and usually provided on a year-by-year basis (cliquet-style) for the whole contract duration. Contracts often have a very long duration with savings accumulation periods of over 40 years. ${ }^{1}$ In view of (higher) equity capital requirements under new solvency

\footnotetext{
*Hato Schmeiser and Joël Wagner are with the Institute of Insurance Economics, University of St. Gallen, Kirchlistrasse 2, CH-9010 St. Gallen.

${ }^{1}$ Contracts are closed for a period averaging almost thirty years in the German market, even though about half of the contracts are cancelled before maturity (see BVZL International Secondary Markets for Life Insurance, www.bvzl.de). For
} 
regulations (see, e.g., Solvency II in the European Union) and the current capital market situation with low-return investment opportunities, long-term interest rate guarantees in life insurance contracts are becoming more and more difficult to manage. Current discussions in the industry include the introduction of time-limits for the guarantees (e.g., for the first ten years) or a relative definition of the guarantees that renders them adjustable throughout the contract duration (e.g., as a percentage of the return on government bonds), see also Heinen (2011). Recently, German life insurance group Nürnberger announced its intention to develop a new type of conventional insurance contracts without an ex-ante fixed interest rate guarantee for the whole contract duration (see Fromme, 2011).

The guaranteed interest rate and policyholder participation are common examples of implicit option elements in standard type policies issued in the U.S., Europe, as well as in Japan (see Grosen and Jorgensen, 2000). If these guarantees are not properly valued and accordingly hedged they may represent a hazard for the insurer solvency. From the late 1980s through the 1990s a large number of massive life insurer defaults occurred, including, e.g., the First Executive Corporation (U.S.), Garantie Mutuelle des Fonctionnaires (France) and Nissan Mutual Life (Japan). More recently, in the early 2000s the British life insurer Equitable Life had to stop taking new business and German Mannheimer Lebensversicherung ran into financial distress. ${ }^{2}$ In these cases, the companies were unable to meet obligations which arose from investment guarantees they provided to their customers.

As a response to the insolvency threat to insurance companies these return guarantees are now widely regulated by local authorities. The underlying trigger for the defaults is typically a change in capital market returns when market interest rates fall to particularly low levels compared to the guaranteed rates. Following 69 insolvencies in the U.S. in the years 1987 to 1989, regulation was enacted in 1990 requiring, inter alia, higher contributions to mandatory securities valuation reserves (see Wright, 1991, pp. 91-95), with the effect that policies with high embedded guarantees were less commonly offered. In the following years, further regulatory and accounting initiatives were launched, evidence of heightened concern over interest rate guarantees (see, e.g., Grosen and Jorgensen, 2002, p. 66). Since 1992, European Union life insurance directives (see European Union, 1992, Art. 18, confirmed by European Union, 2002, Art. 20) have defined upper bounds for interest rate guarantees. Grosen and Jorgensen (2002, Table 1) summarize maximum rates for several countries: While the U.S. has not set a maximum rate, European Union countries as well as Japan have established such limits (see, e.g., Cummins et al., 2007, and Eling and Holder, 2012, for a detailed comparison).$^{3}$

European Union directives require that interest rate guarantees do not exceed $60 \%$ of the rate of return on government debt. Local maximum rates are thus adapted over time in line with prevailing rates in the capital market. For example, in the light of currently low returns on government bonds, the German Federal Ministry of Finance has adjusted the maximum interest rate guarantee for life insurance

the United States (U.S.), Klein and Butala (2004) state that policies and their long-term guarantees often last more than 50 years.

${ }^{2}$ For a detailed review of bankruptcies due to implicit policy guarantees, see Wright (1991), Briys and de Varenne (1997), Ballotta and Haberman (2003), Ballotta et al. (2003) or Grosen and Jorgensen (2002) and the references cited therein.

${ }^{3}$ Aside from regulation on guaranteed rates and policyholder participation, local solvency capital requirements and contributions to guaranty schemes apply. A broad overview of different countries' solvency regulation can be found, e.g., in Eling et al. (2007, Table 1). Schmeiser and Wagner (2012, Table 1) give an international review of guaranty funds in force. 
contracts from 2.25\% to 1.75\% with effect from 1st January 2012 (German Federal Ministry of Justice, 2011). Similarly, the Swiss Financial Market Supervisory Authority has reduced the maximum technical interest rate for policies in Swiss francs to $1.50 \%$ (see www.finma.ch). This adjustment to the maximum interest rate applies only to new contracts, whereas insurers still have older contracts in their portfolio with guarantees of up to $4 \%$ (maximum rate allowed for new contracts in Germany between 1995 and 2000). Furthermore, it should be borne in mind that regulation parameters are adjusted in response to developments in the capital markets, and that the time-lag between market changes and regulatory adjustments may be particularly large when the markets are moving relatively fast. The maximum rate also varies from country to country, even within the European Union. Although the regulator only defines an upper bound for the interest rate, this bound is currently the one offered in practice and guaranteed by almost all insurance companies in their contracts to policyholders. This situation is mainly due to "intuitive" arguments in insurance distribution and "naive" contract assessment, where risk-averse customers are offered the highest possible guarantees, even if these may inhibit the future chances of higher returns for policyholders. In fact, each time supervisory authorities announce a lowering of the maximum rate, insurance distributors continue to use the higher guaranteed rate still in force as a selling proposition. With regard to these considerations, a core objective of this paper will be to determine at what level the regulator should set the maximum value of the interest rate guarantee when taking into account policyholder utility. Furthermore, and with special consideration of the introduction of higher solvency capital requirements in the European Union, we will focus on the interaction of both regulations on the asset allocation of life insurers. In fact, we observe that while in the past ten years the risk-free interest rate (e.g., the return of high-rated government bonds) has approached the interest rate guarantee, life insurers have substantially reduced their investment in stocks.

Different perspectives have to be considered when assessing the value of an insurance contract. The regulator typically evaluates contracts, on the one hand, using risk management measures like, e.g., the related likelihood of insolvency or inherent possible deficits, while supervising compliance with regulations in force. On the other hand, the regulator is required to take the policyholder viewpoint into account and considers, e.g., the utility to the individual when defining regulatory parameters. Furthermore the reactions of the different companies need to be considered. Among these, the implementation of the parameter settings is of crucial importance, as well as the pricing strategy. Under the assumptions of a competitive market, insurance companies can set risk-adequate prices only, allowing for an appropriate return to shareholders. These different perspectives are considered in a detached way, for example, in the work of Gatzert et al. (2012), where the authors analyze the value creation for customers in participating life insurance contracts in different situations. Core results include the analysis of customer value under conditions of deterministic and stochastic wealth. Further research done on participating life insurance contracts relevant in our context includes, e.g., the study by Grosen and Jorgensen (2000) which considers the fair valuation of life insurance liabilities and analyzes the impact of interest rate guarantees and other options on participating contracts. Gatzert and Kling (2007) present extensive analysis of participating life insurance contracts, in particular using the concept of market valuation and introducing corresponding forms of risk measurement. Like Gatzert and Kling (2007), Briys and de Varenne (1997) 
and Grosen and Jorgensen (2002) take a contingent claim approach to the market valuation of equity and liabilities in life insurance. Specifically, they analyze insolvency risk and provide analytical results. A numerical assessment of the impact of surplus distribution and interest rate guarantees on the risk exposure of life insurers is presented by Kling et al. (2007a,b).

Furthermore, substantial research considers the above-mentioned viewpoints separately or in pairs. Analyses reflecting the insurance company perspective can be found, for example, in the works of Bacinello (2003), Ballotta et al. (2006), Gatzert (2008), and Bohnert and Gatzert (2012). The latter apply option pricing theory to participating life insurance contracts in order to value the policies. Myers and Read Jr. (2001) and Gründl and Schmeiser (2007) study an insurer's pricing and risk management in relation to equity capital and capital allocation. Literature considering the policyholder perspective is typically based on utility theory. While Berketi (1999) considers a mean-variance framework to assess policyholder preferences, Broeders et al. (2011) assume that their representative customer has power utility. Finally, the regulator's position is analyzed through the setting of minimum solvency requirements. While the current state of development of the European Solvency II framework, for instance, can be found in European Union (2009) and European Commission (2010), a broad overview of risk management measures is given, for example, in the work by Gatzert and Kling (2007).

In this paper, we consider the question of what would be an appropriate maximum value for the regulator to set for the guaranteed interest rate in participating life insurance contracts. In our model, we assume that (A) all insurers adopt in practice this maximum value permitted by the regulator for the interest rate guarantee and that, similarly, (B) the minimum policyholder participation rate set by the regulator is adopted. We include $(\mathrm{C})$ a safety requirement set by the regulator defining an upper bound on the contract insolvency probability. In our model, the supervisor also assumes that (D) the market is competitive, meaning that stakes risk-adequately priced, i.e., the net present value of future cash flows is zero for both policyholders and equity holders. The above assumptions (A) to (D) have implications for the insurance companies and its stakeholders: First, the conditions set the possible levels of equity capital and simultaneously the insurer's asset allocation. Second, this implicitly determines the policyholder payoff and hence the individual utility. The latter has to be taken into account by the regulator when determining the maximum guaranteed interest rate. A synoptical overview of the assumptions and the implications considered in this work is given in Figure 1 (see Section 2.3).

Our findings include four key results. First, in our framework, the above mentioned assumptions fully determine the insurer's asset allocation and the underlying equity capital in a reference situation. Second, when assessing the sensitivity of the insurer's position to changes in the capital markets, i.e., for example, to variations in the risk-free interest rate, our results show that if the risk-free interest rate approaches the interest rate guarantee (which is currently the case in many European countries), the insurer's position follows with equity capital drifting to zero, while the insurer's investment tends to become more and more riskless. Consequences include that the policyholder guarantees offered become worthless and that the insurer faces residual costs due to excessive equity capital which may not be reduced at short notice. In addition, no upside potential from the holding of risky investments can be provided to the policyholders in such a situation. Third, we show how the regulator should set (the bound on) the guaranteed interest 
rate in order to optimize the policyholders' utility on contract payoff. Finally, we show that our results are stable when considering different safety levels and applying the model to contracts of different durations.

The remainder of this paper is organized as follows: Secion 2 introduces our model framework specifying the contract payoff and the stakes of the involved parties (Section 2.1). In Section 2.2 the different regulatory requirements and assumptions are presented in detail; Section 2.3 summarizes the different interrelations. Section 3 first presents the implications for the insurer's position in a reference situation (Section 3.1). An assessment of the influence of changes in the risk-free interest rate and a discussion of the consequences is given in Section 3.2. In Section 3.3 policyholder utility is calculated and conclusions for the optimal maximum guaranteed interest rate are derived. Part 3.4 completes Section 3 with an illustration of selected parameter sensitivities. The conclusion in Section 4 reviews our key findings.

\section{Model framework}

In the following, we develop a basic model of life insurance. Since changes in market interest rates guaranteed interest rate, risk-free investment interest rate, return on risky capital market investments affect the policyholders' savings account, we focus solely on the savings premium without taking biometric risk into account. ${ }^{4}$ For the latter we suppose that a separate premium for a death benefit payment is owed. ${ }^{5}$ Our main interest lies in the financial risk situation for the full contract term. Hence we do not take early surrender and deaths into account and consider that indemnity payments to the policyholder are only made at the term of the contract. Furthermore we do not consider transaction costs.

Our aim is to take insolvency risk explicitly into account. We therefore consider a contingent claim model framework for an insurance company based on a model first proposed by Doherty and Garven (1986), and inspired by the standard models of Briys and de Varenne (1997) and Grosen and Jorgensen (2002). We adopt a neo-classical economic framework, i.e., we assume, in particular, that capital markets are complete and arbitrage-free. The model framework used allows for a risk-adequate positioning of the stakeholders involved. We adjust it for two stakeholders, namely policyholders and equity holders of the insurance company. The value of the default put option introduced below is a measure of the insurer's safety level (see also, for example, Phillips et al., 1998, and Gründl and Schmeiser, 2007).

Besides competitive market conditions, we assume that the regulator requires a certain safety level. In the framework, an upper-boundary condition on the ruin probability at the term of the contract is considered. Since no payouts are due within the contract duration, we allow the equity capital to become negative during the term of the contract (see, e.g., Gatzert and Kling, 2007).

In the following we present our model and detail the contract payoff and the different parties' stakes (Section 2.1). Then we introduce the regulator's viewpoint and detail the assumptions used to value the

\footnotetext{
${ }^{4}$ We consider endowment policies where the policyholder's premium payment (after deduction of transaction costs) is typically split into two parts: a premium for term life insurance covering mortality risk, and a savings premium which is credited to the policy assets. The premium payment considered in the following exposition corresponds to the savings premium only.

${ }^{5}$ Under the assumption that mortality risk is diversifiable, it can be dealt with using discounted expected values of future cash flows when writing a large number of contracts.
} 
contract (Section 2.2).

\subsection{Contract payoff and stakeholder claims}

The focus of our analysis is on participating endowment contracts similar to those offered in many European countries. The present setting, inspired from Grosen and Jorgensen (2000), is closest to the one described in Gatzert et al. (2012) whose description we partially adopt in the following. At inception of the contract, policyholders pay a single up-front premium $P_{0},{ }^{6}$ and the insurance company equity holders make a contribution of equity capital $E_{0}$. The insurance company's initial assets are denoted by $A_{0}$ corresponding to the total value of initial payments $A_{0}=P_{0}+E_{0}$. These assets are invested in the capital market, leading to uncertainty about the value of the insurer's assets $A_{t}, t=1, \ldots, T$, where $T$ denotes the contract duration.

The life insurer's assets $A_{t}$ are invested in two asset classes (two-asset model, see, e.g., Merton, 1969). One part, denoted $(I)$, is invested risk-free, another part $(I I)$ is invested in a risky asset class. In the following, we refer to the portfolio composition in terms of returns: different portfolio compositions are generated by assuming that the return on assets is $\gamma \cdot r^{(I)}+(1-\gamma) \cdot r^{(I I)}$, the different ' $r$ 's representing one-period continuous returns and $\gamma$ the asset allocation parameter. The evolution of the assets for $t=1, \ldots, T$ is given by

$$
A_{t}=A_{t-1} \cdot \exp \left[\gamma \cdot r^{(I)}+(1-\gamma) \cdot r^{(I I)}\right]
$$

with initial condition $A_{0}$.

While we have $r^{(I)}=r_{\mathrm{f}}$, with $r_{\mathrm{f}}$ denoting the risk-free return, the second return $r^{(I I)}$ is modeled through a normal distribution. Let $W_{t}^{\mathbb{P}}, t=0, \ldots, T$, be a standard Brownian motion on a probability space $(\Omega, \Phi, \mathbb{P})$ and $\Phi_{t}, t=0, \ldots, T$, be the filtration generated by the Brownian motion. In this setting, and under the real-world measure $\mathbb{P}$, the stochastic process is characterized by a deterministic drift $\mu_{\mathrm{GBM}}$ and volatility $\sigma_{\mathrm{GBM}}$ so that the related one-period return writes out as $r^{(I I)}=r_{t, \mathrm{GBM}}=\mu_{\mathrm{GBM}}-$ $\sigma_{\mathrm{GBM}}^{2} / 2+\sigma_{\mathrm{GBM}}\left(W_{t}^{\mathbb{P}}-W_{t-1}^{\mathbb{P}}\right), t=1, \ldots, T$. Hence the evolution of the insurer's investment portfolio defined in Equation (1) is expressed by

$$
A_{t}=A_{t-1} \cdot \exp \left[\gamma \cdot r_{\mathrm{f}}+(1-\gamma) \cdot\left(\mu_{\mathrm{GBM}}-\sigma_{\mathrm{GBM}}^{2} / 2+\sigma_{\mathrm{GBM}}\left(W_{t}^{\mathbb{P}}-W_{t-1}^{\mathbb{P}}\right)\right)\right],
$$

for $t=1, \ldots, T$, and intial condition $A_{0}$ (see, e.g., Björk, 2004).

In the case the insurer is solvent at time $t=T$, the assets $A_{T}$ exceed the liabilities to the policyholders. The value of the available assets is closely linked to the investment strategy, here parameterized by the risky investment $\left(\mu_{\mathrm{GBM}}, \sigma_{\mathrm{GBM}}\right)$, the riskless rate of return, and the asset allocation parameter $\gamma$. The amount of policyholder liabilities at maturity $T$ is determined by three further parameters in our model.

\footnotetext{
${ }^{6}$ In many European countries, endowment contracts have the highest share in life insurance sales. In Germany, for example, about one third of all life insurance contracts are (traditional) endowment insurance policies (Gesamtverband der Deutschen Versicherungswirtschaft e.V. (GDV), 2012, Table 34). Of these, 27\% are single premium life insurance contracts (GDV, 2012, Table 33). Following Gatzert et al. (2012) and several other authors (see, e.g., Grosen and Jorgensen, 2000; Ballotta et al., 2006; Gatzert and Kling, 2007), and for ease of exposition, we only consider single premium contracts. However, our exposition could also be adapted to allow for policies with periodic premium payments. An analysis of participating endowment contracts with regular premium payments and which give customers the right to surrender their policy is a focus of the work by Schmeiser and Wagner (2011).
} 
The first parameter is the initial premium payment $P_{0}$. The second is the guaranteed minimum annual interest rate $g$ for policyholder reserves. In many countries, this interest rate is regulated by law by means of an upper bound which is adjusted periodically, depending on capital market conditions. The third parameter is the annual surplus distribution rate $\alpha$. In general, this rate is regulated too, similar to the interest rate guarantee (e.g., Germany, Switzerland, and France). Hence, in the case of positive market developments, the policyholders participate in the insurer's investment returns that exceed the guaranteed interest rate.

The policyholder account $P_{t}$ is initialized in $t=0$ with the payment of the up-front premium $P_{0}$. Annually, at times $t=1, \ldots, T$, the value of the account $P_{t}$ earns an interest rate $r_{t}$ which is the greater of the guaranteed interest rate $g$ or a fraction $\alpha$ of the annual return $\left(A_{t} / A_{t-1}-1\right)$ on the insurer's investment portfolio. Note that this annual participation in turn becomes part of the guarantee (socalled cliquet-style guarantee). Thus the policyholder account $P_{t}$ writes out as:

$$
P_{t}=P_{t-1} \cdot\left(1+r_{t}\right)=P_{t-1} \cdot\left[1+\max \left(g, \alpha\left(A_{t} / A_{t-1}-1\right)\right)\right],
$$

where $t=1, \ldots, T$.

We denote by $D_{T}$ the cost of insurer insolvency at the term of the contract. These costs are referred to as the default put option (see, e.g., Doherty and Garven, 1986, and Butsic, 1994) defined by

$$
D_{T}=\left(P_{T}-A_{T}\right)^{+},
$$

where $(\cdot)^{+}$stands for $\max (\cdot ; 0)$. In the case where the available assets $A_{T}$ at the term of the contract exceed the value of the policyholder account $P_{T}$, we have $D_{T}=0$. In the adverse case where the assets $A_{T}$ are insufficient to cover the value of the policyholder account $P_{T}$, the cost of insolvency corresponds to the positive difference of $P_{T}-A_{T}$.

Hence, taking insolvency risk into account, the policyholder payoff at maturity $L_{T}$ is given by

$$
L_{T}=P_{T}-D_{T}=P_{T}-\left(P_{T}-A_{T}\right)^{+} .
$$

Consequently, the equity holder stake $E_{T}$ at time $T$, which corresponds to the remaining assets after the policyholder liabilities have been paid out, corresponds to

$$
E_{T}=A_{T}-L_{T}=\left(A_{T}-P_{T}\right)^{+} .
$$

\subsection{Main assumptions, risk management constraints, and contract valuation}

In the following, we describe in detail the regulatory requirements taken into account and the insurance supervisor's assumptions about the different stakeholders. In particular, we consider the regulation on the contract parameters and a solvency requirement. Furthermore we assume that competitive markets define the pricing strategy and that policyholder utility is measured through a preference function. 


\section{Regulation of traditional life insurance contract parameters}

Regulation of traditional life insurance contracts and in particular of participating policies includes bounds on the minimum interest rate guarantee $g$ and the participation rate $\alpha$ in the annual return of the insurer's asset portfolio. In the European Union and in Switzerland the regulatory directives prescribe an upper bound for the interest rate guarantee and a lower bound for the participation rate. The upper bound on the interest rate guarantee equals the guarantee $g$ offered in practice by all insurers in their contracts. The participation $\alpha$ is also often an exact adoption by insurers of the prescribed bound. This leads us to state the following two hypotheses:

(A) The regulatory maximum value for the guaranteed interest rate $g$ is equal to the value of the guarantee adopted in practice by insurers for new contracts.

(B) The minimum policyholder participation $\alpha$ corresponds precisely to the minimum participation rate set by the regulator.

\section{Solvency requirement}

The regulator takes a risk management perspective and requires insurance companies to maintain a certain safety level. For example in the planned European Union Solvency II requirements (see, e.g., European Union, 2009, and European Commission, 2010) this translates into an upper bound on the ruin probability. Since no payouts are made before time $T$, risk is interpreted as a possible shortfall at maturity. Hence, we define a shortfall if the value of the assets at maturity $A_{T}$ does not cover the value of the policyholder account $P_{T}$, i.e., if $A_{T}<P_{T}$ (see, e.g., Grosen and Jorgensen, 2002). We assess risk under the empirical measure $\mathbb{P}$ and introduce the ruin probability at the contract term $T$ as follows,

$$
R_{T}=\operatorname{Prob}\left(A_{T}<P_{T}\right)
$$

We suppose that the regulator's solvency requirement is

$$
R_{T} \leq \epsilon,
$$

with $0 \leq \epsilon \leq 1$, hence requiring the ruin probability in $T$ be bound from above by $\epsilon$.

Insurance companies may "optimize" their position by precisely fulfilling the requirement (8). By doing so, the insurer can typically minimize capital requirements. Thus, we refer in the following to the exact fulfillment of (8) corresponding to the minimum safety requirement where the ruin probability $R_{T}$ is equal to the upper bound $\epsilon$, and define condition $(\mathrm{C})$ as follows:

(C) The regulatory safety level is met exactly by the insurance companies, i.e., the contract ruin probability is such that $R_{T}=\epsilon$. 


\section{Assumption of a competitive market}

In our model we assume a complete, perfect, frictionless and competitive market. Under the assumption of an arbitrage-free capital market, claims are evaluated under the measure $\mathbb{Q}$ using the concept of riskneutral valuation. Under $\mathbb{Q}$, the drift of the asset process changes from $\mu_{\mathrm{GBM}}$ to the risk-free interest rate $r_{\mathrm{f}}$, and the evolution of the assets $A_{t}, t=1, \ldots, T$, is then given by (cf. Equation 2):

$$
A_{t}=A_{t-1} \cdot \exp \left[\gamma \cdot r_{\mathrm{f}}+(1-\gamma) \cdot\left(r_{\mathrm{f}}-\sigma_{\mathrm{GBM}}^{2} / 2+\sigma_{\mathrm{GBM}}\left(W_{t}^{\mathbb{Q}}-W_{t-1}^{\mathbb{Q}}\right)\right)\right],
$$

with $\mathbb{Q}$-Brownian motion $W_{t}^{\mathbb{Q}}$ and initial condition $A_{0}$. Thus, the values of the policyholder $\left(\Pi_{0}^{\mathrm{P}}\right)$ and of the equity holder $\left(\Pi_{0}^{\mathrm{E}}\right)$ stakes under the risk-neutral measure are given by:

$$
\Pi_{0}^{\mathrm{P}}=E_{0}^{\mathbb{Q}}\left[L_{T}\right]=E^{\mathbb{Q}}\left[e^{-r_{\mathrm{f}} \cdot T} \cdot L_{T}\right],
$$

and

$$
\Pi_{0}^{\mathrm{E}}=E_{0}^{\mathbb{Q}}\left[E_{T}\right]=E^{\mathbb{Q}}\left[e^{-r_{\mathrm{f}} \cdot T} \cdot E_{T}\right],
$$

respectively with $L_{T}$ and $E_{T}$ defined in Equation (5) and (6).

The assumption of a competitive market implies that fair prices for the contracts are set. From an equity holder perspective this means that risk-adequate returns are generated on the invested capital. By setting competitive prices an insurance company can ensure appropriate returns to equity holders, thereby attracting investors. From the policyholder viewpoint this implies that the present value of the policyholder payoff under the risk neutral martingale measure is equal to the present value of the upfront premium $P_{0}$ paid by the policyholder (see, e.g., Doherty and Garven, 1986). Hence the competitive market condition implies that the net present value of the policyholder payoff equals to zero, i.e., $\Pi_{0}^{\mathrm{P}}=P_{0}$. This equation leads to $\Pi_{0}^{\mathrm{E}}=E_{0}$ since no arbitrage possibilities are assumed. In the following we denote by $N P V$ the net present value of the policyholder payoff, defined by

$$
N P V=\Pi_{0}^{\mathrm{P}}-P_{0} .
$$

The condition of a competitive market implies that the pricing is appropriate for the policyholders and the equity holders if (and only if)

$$
N P V=0 .
$$

Hence we consider the following condition (D) in our model:

(D) A competitive market is assumed, thus implying risk-adequate prices such that $N P V=0$.

\section{Policyholder contract valuation}

Finally, and as part of its duty to protect policyholders' interests, the regulator should take into account the policyholder value calculus. Since policyholders may not be able to diversify their claims to the same extent as insurers (no duplication of future cash flows may be possible, see, e.g., Gatzert et al., 2012), policyholders judge the value rather on the basis of individual preferences. The set of all competitive 
contracts offered involves differences regarding the fulfillment of policyholder preferences. In what follows, the customers contract value is measured through the expected policyholder utility or the value of the related certainty equivalent. In the sequel, and as done, e.g., in Broeders et al. (2011), we assume the representative policyholder possessing wealth $w$ to have a power (isoelastic) utility function given by

$$
U(w)=\frac{w^{1-\rho}}{1-\rho},
$$

where $\rho>0, \rho \neq 1$, is the Arrow-Pratt constant coefficient of relative risk aversion. Here decision-making is unaffected by scale. An increasing risk aversion of the policyholder is modeled through an increase of the coefficient $\rho$. We will base the policyholder utility calculus on the policyholder payoff $L_{T}$. In order to assess the value of different payoff distributions we will derive in each situation the certainty equivalent $C E$ defined through the following relation:

$$
U(C E)=E\left[U\left(L_{T}\right)\right] .
$$

Hence the certainty equivalent $C E$ corresponds to the amount of payoff whose utility $U(C E)$ equals the expected value of the utility of the payoff distribution $L_{T}$. The higher the value of the certainty equivalent $C E$, the higher the utility and hence the contract value from the policyholder perspective.

\subsection{Overview of assumptions and interrelations}

This section summarizes the interrelation between the regulator's assumptions and the implications for insurance companies and policyholders. Figure 1 gives a synoptical overview of the various relationships we analyze in the remainder of this work.

The focus of our research concerns the optimal setting of the maximum value for the guaranteed interest rate by the regulator. First, the chart in Figure 1 reviews the different assumptions (A) to (D) concerning the use in practice of the interest guarantee and participation rate, the solvency requirement, and the competitive market. Second, the implications for the insurance companies with simultaneous effects on the level of equity and the asset allocation are depicted. Third, the consequences for the policyholder payoff and the related utility are shown. Finally, the graph shows how the policyholder utility is taken into account by the regulator when determining the maximum guaranteed interest rate.

\section{The interaction between the value of the interest rate guar- antee and the asset allocation of a life insurance company}

In this section we apply the model framework introduced and analyze the regulator's definition of the maximum guaranteed interest rate. Key elements of the study will be the conditions (A) to (D) introduced in Section 2.2. Herein the derivation of the insurer's level of equity capital and asset allocation on the one hand, and the calculation of the policyholder payoff and utility outcome on the other hand, will be of crucial importance. 


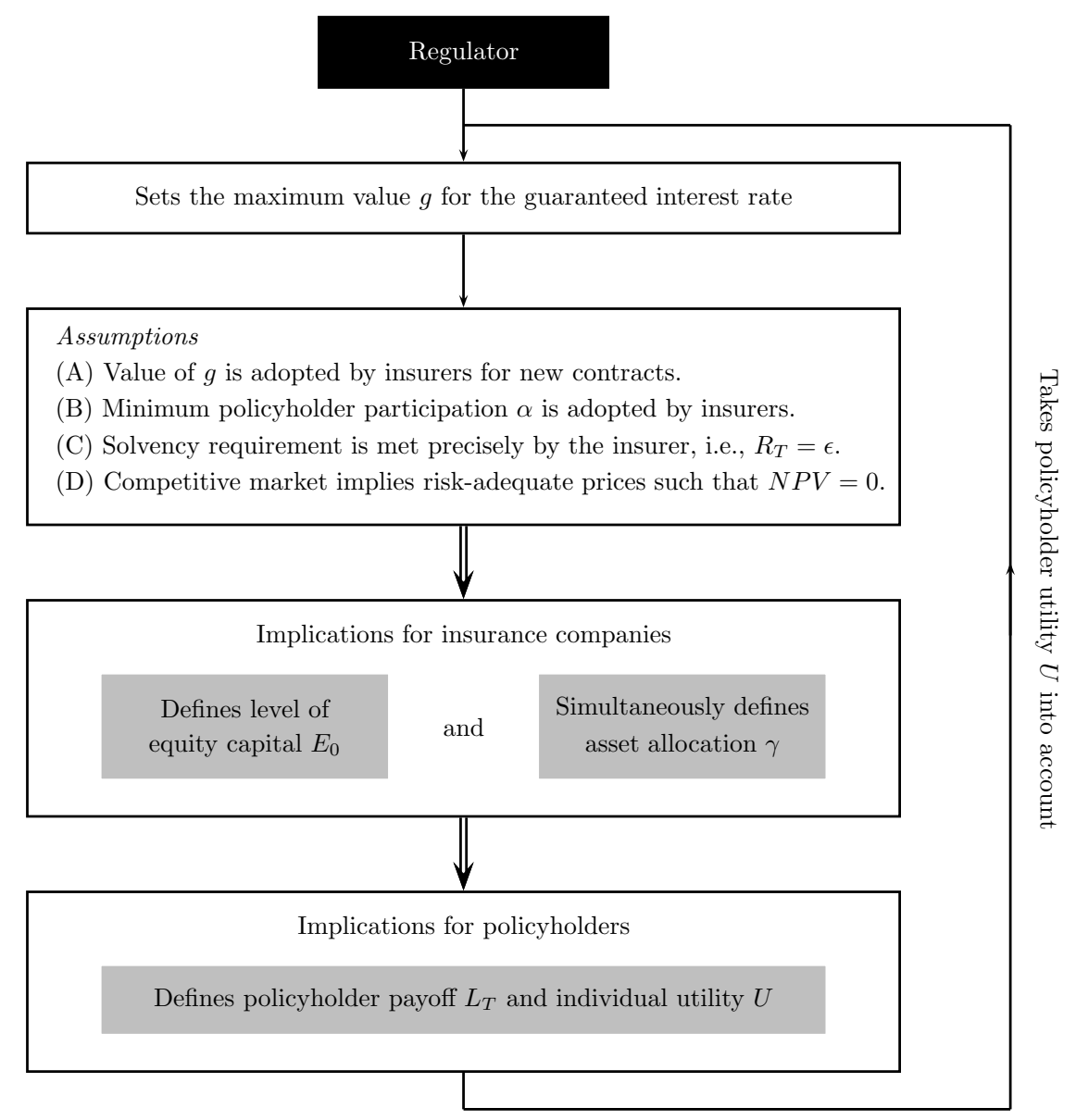

Figure 1: Overview of the regulator's setting the maximum value $g$ for the guaranteed interest rate. Based on the assumptions (A) to (D) the direct implications for insurance companies and the policyholders are depicted. The regulator takes policyholder utility into account when determining $g$.

Even though an analytical expression can be derived for the value at time zero of the policyholder account $P_{T}$ under the risk-neutral measure $\mathbb{Q}$, this is no longer possible for the policyholder payoff. Even if the analytical expression of $P_{T}$ (see iterative definition in Equation 3) can be reduced to involve just one maximum operator, the expression of $D_{T}$ (see Equation 4) introduces a second use of the maxfunction (nested max operators with stochastic variables), so that no closed form formulation can be written out for the default put option $D_{T}$ and hence neither for the policyholder payoff $L_{T}$ (Equation 5) nor the equity holder stake at maturity $E_{T}$ (Equation 6). In order to evaluate the different stakes, to verify the competitive market condition and solvency requirement, and finally to value the contract in different situations, a Monte Carlo simulation is utilized to obtain numerical results. In each situation at least $N=100000$ different Monte Carlo realizations are simulated. The evaluation of the possible combinations for the equity capital $E_{0}$ and the asset allocation $\gamma$ is done in such a way that the results 
can be presented with an absolute precision of $\pm 10^{-3}$.

In the following (Section 3.1), we first introduce a reference situation wherein we set the values for the various model parameters which will serve as a starting point. After detailing the basis setting, we exemplify the implications on the insurer's position with regard to its equity capital and asset allocation. Next, we analyze the impacts on this position under a variation of the risk-free interest rate while keeping everything else unchanged (Section 3.2). When the values of the risk-free interest rate and the interest rate guarantee approach each other, the insurer's asset allocation becomes almost risk-free and the equity capital must decrease in order to provide a risk-adequate return for the equity holders. A detailed discussion follows the presentation of the results. In Section 3.3 we evaluate the policyholder utility at three different levels of risk aversion and discuss how the regulator should set the interest rate guarantee in order to improve policyholder utility. Finally, we show the stability of the results in Section 3.4 where we analyze their sensitivity with respect to the required safety level and the insurance contract length.

\subsection{The insurance company's position in the reference situation}

The aim of this section is to describe the full set of model parameters in order to define a reference situation. First we present and discuss the assumptions underlying the model parameterization, and then we illustrate the implications for an insurance company. In the reference setting and under the regulator's assumptions and conditions (see Section 2.2 and Figure 1 for an overview), the insurer's level of equity capital with respect to premium income and its asset allocation as a combination of a risk-free and a stock market investment are simultaneously determined.

\section{Parameterization of the reference setting}

In the following we detail our assumptions and the parameter settings used for the reference situation.

Savings premiums and contract length. We assume the policyholder pays an up-front premium $P_{0}$ and takes out a contract with a duration $T$ (years). For simplification, we set $P_{0}=1$ currency unit (C.U.) and $T=10$. With $P_{0}$ set to unit, the values of the equity capital $E_{0}$ can be interpreted more easily when using the debt-equity ratio $P_{0} / E_{0}$. Results for different values of the contract length $T$ are reported at the end of this chapter in Section 3.4.

Regulatory environment. In many countries regulations concerning policy reserves define an upper bound (maximum) for the guaranteed annual interest rate until maturity. Furthermore, law generally ensures that a minimum proportion of the investment earnings on book values are credited to the policyholder account. The maximum guaranteed interest is defined through regulation and adapted to the evolution of the markets. As mentioned in the introduction (see assumption A), insurance companies typically offer this maximum interest rate in their contracts to policyholders. Hence, in the following exemplary analysis we assume insurers to use this upper bound and refer to the value in force in Germany. Thus we set $g=1.75 \%$ (see German Federal Ministry of Justice, 2011, §2). The policyholder participation $\alpha$ is bounded from below and also precisely adopted by the industry (assumption B). In Germany, the minimum amount for the participation parameter is currently set at $90 \%$ (see German Federal Ministry of Justice, 2008, §4). We will use this minimum value in our reference situ- 
ation and set $\alpha=90 \%$. Let us point out that these regulatory settings are very close to the ones in force in other countries. In Switzerland, for example, the Swiss Financial Market Supervisory Authority (FINMA) also reviewed the maximum technical interest rate on 1st January 2012, adjusting it to $1.50 \%$ (see FINMA at www.finma.ch). Similarly to German law, Swiss legislation also specifies that at least $90 \%$ of the sum of the profit components determined in the annual accounts must be used for the benefit of the policyholders (so-called minimum quota, Art. 37, §4 of the Insurance Supervision Act and Art. 147 of the Supervision Ordinance, see FINMA at www.finma.ch). Finally, the regulator's safety requirement sets an upper bound on the ruin probability $R_{T}$ in $T$ (see Equations 7 and 8, and condition $\mathrm{C}$ ). To start with, we set this bound at $\epsilon=0.5 \%$. Results for different safety levels $\epsilon$ are reported at the end of this chapter in Section 3.4.

Capital market conditions. First, we define the risk-free interest rate determined by market conditions. Since market remuneration rates fluctuate, we take the value of $r_{\mathrm{f}}=3 \%$ as a starting point. This reflects the current value of AAA-rated euro area central government bonds (10-year yield) and corresponds to the value considered by the regulator when determining the upper bound for the interest rate guarantee. ${ }^{7}$ As a core element of our analysis, this will be varied to reflect different market situations, see, e.g., in Section 3.2. In addition, we define the available capital market investment possibility through a parameterization of the performance of the stock market. We assume that the insurance company may invest in stocks yielding a mean return and standard deviation of $(\mu, \sigma)=(5 \%, 20 \%)$. This corresponds to the long-term evolution of European stock markets. ${ }^{8}$ In our analysis we assume that risk asset returns are normally distributed. Thus the values of the assets $A_{t}$ for $t=1, \ldots, T$ are $\log$-normally distributed (see Equations 2 and 9).

In Tables 1 and 2 we summarize the input parameters for the exemplary reference situation and recapitulate all variable definitions used.

\section{Illustration of the reference situation}

Let us consider first the exemplary reference situation characterized by the parameterization given in Table 1. The objective is to determine the values of the insurer's equity capital $E_{0}$ and the asset allocation $\gamma$ implied by the conditions (A) to (D). While the assumptions (A) and (B) are implemented and fulfilled through the parameterization by the respective values of $g$ and $\alpha$ (see Table 1), our focus will be on the derivation of the level of equity capital and the asset allocation that comply with the solvency requirement (condition $\mathrm{C}$ ) and the competitive market condition (D). Typically only a few combinations of $E_{0}$ and $\gamma$ will comply with both $(\mathrm{C})$ and (D) (for given $g$ and $\alpha$ under assumptions A and B). Depending on the market, and the values of the regulatory and contract parameters, it is possible that no combinations exist.

In order to apply conditions (C) and (D), we study the values of the ruin probability $R_{T}$ at contract

\footnotetext{
${ }^{7}$ In Germany, for example, the maximum guaranteed interest rate is derived from the $60 \%$-return of the euro-area 10 -year government benchmark bond (German Insurance Supervision Act, §65).

${ }^{8}$ Parameter values are calculated based on the performance of the German stock index DAX, which is a blue chip stock market index consisting of the 30 major German companies (50-year-performance, till end of 2011: $\mu=5.0 \%, \sigma=19.9 \%$ ) or the similarly performing European stock index EUROSTOXX 50 consisting of European blue chips (24-year-performance, 1987-2011: $\mu=4.7 \%, \sigma=20.3 \%$ ).
} 


\begin{tabular}{lll}
\hline Parameter & Variable & Value \\
\hline Contract & & \\
Policyholder single upfront premium & $P_{0}$ & 1.0 (C.U.) \\
Contract duration & $T$ & 10 (years) \\
Guaranteed interest rate & $g$ & $1.75 \%$ \\
Annual surplus participation rate & $\alpha$ & $90 \%$ \\
\hline Capital market conditions & \multicolumn{3}{l}{} \\
Risk-free rate of return & $r_{\mathrm{f}}$ & $3.0 \%$ \\
Drift of the geometric Brownian motion process & $\mu_{\mathrm{GBM}}$ & $7.0 \%$ \\
Volatility of the geometric Brownian motion process & $\sigma_{\mathrm{GBM}}$ & $20.0 \%$ \\
\hline Solvency regulation & \multicolumn{2}{l}{} \\
Safety requirement (upper bound on ruin probability in T) & $\epsilon$ & $0.5 \%$ \\
\hline
\end{tabular}

Table 1: Input parameters for the reference case.

\begin{tabular}{ll}
\hline Parameter & Variable \\
\hline Equity capital at contract inception & $E_{0}$ \\
Asset allocation (share of assets invested risk-free) & $\gamma$ \\
Value of insurer's assets / investment portfolio at times $t=0,1, \ldots, T$ & $A_{t}$ \\
Value of policyholder account at times $t=0,1, \ldots, T$ & $P_{t}$ \\
Cost of insurance insolvency at the contract term & $D_{T}$ \\
Policyholder payoff at maturity $T$ & $L_{T}$ \\
Equityholder stake at time $T$ & $E_{T}$ \\
Ruin probability at the contract term & $R_{T}$ \\
Net present value of the policyholder payoff & $N P V$ \\
Policyholder individual utility at maturity & $U\left(L_{T}\right)$ \\
\hline
\end{tabular}

Table 2: Variables used in the model.

maturity and the net present value $N P V$ of policyholders' claims in the two-dimensional space of insurer's equity capital $E_{0} /$ asset allocation $\gamma$. Considering jointly both restraining conditions (C) and (D), i.e., $R_{T}=\epsilon$ and $N P V=0$, the implications for $E_{0}$ and $\gamma$ can be illustrated graphically. Figure 2 reports the condition on the ruin probability (dashed curve) and the competitive market condition (solid curve). The single intersection point of both lines gives the equilibrium combination where both conditions are fulfilled. In the sequel, this combination of equity capital and asset allocation will be denoted by the pair $\left(E_{0}^{\mathrm{eq}}, \gamma^{\mathrm{eq}}\right)$. In the case with $r_{\mathrm{f}}=3 \%$ illustrated here, this intersection point is given by $E_{0}^{\mathrm{eq}}=0.108$ (C.U.), $\gamma^{\mathrm{eq}}=0.887$.

Furthermore, given that the ruin probability decreases with increasing $E_{0}$ and increasing $\gamma$, the set of $\left(E_{0}, \gamma\right)$ combinations complying with the weak form of condition $(\mathrm{C})$, namely, $R_{T} \leq \epsilon$ (see Equation 8 ), and condition (D) is given by the points on the curve $N P V=0$ (solid curve) for values of $E_{0} \geq E_{0}^{\text {eq }}$ (i.e., the solid arc to the right of the intersection point $\left(E_{0}^{\mathrm{eq}}, \gamma^{\mathrm{eq}}\right)$ in Figure 2$)$. 


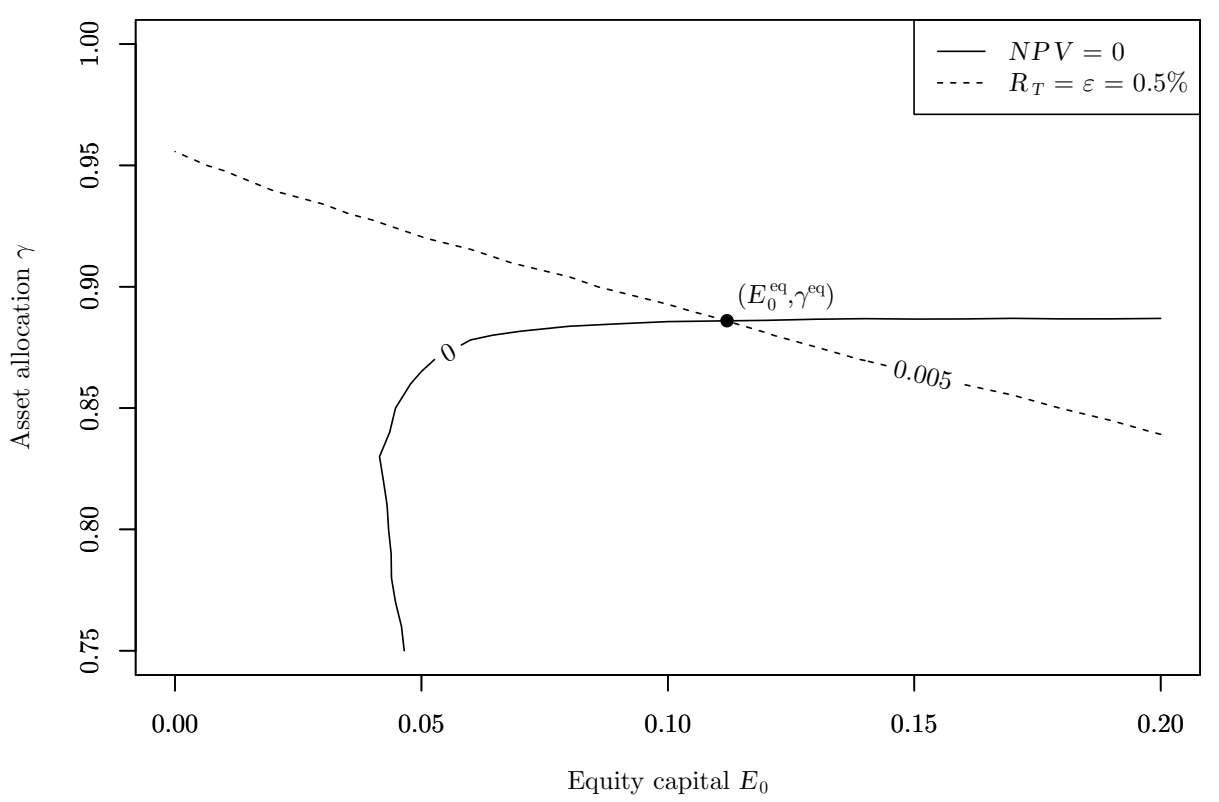

Figure 2: Representation of the equity capital and asset allocation combinations $\left(E_{0}, \gamma\right)$ corresponding to the competitive market condition $N P V=0$ (solid curve) and a ruin probability $R_{T}=\epsilon=0.005=0.5 \%$ (dashed curve). Their intersection complying with both conditions is denoted by $\left(E_{0}^{\mathrm{eq}}=0.108, \gamma^{\mathrm{eq}}=\right.$ $0.887)$.

\subsection{Impact of changes in the risk-free interest rate on the insurer's asset allocation and capital structure}

In the reference situation parameterized in Table 1, the conditions (A) to (D) introduced in Section 2.2 imply that the possible insurer's equity capital and asset allocation $\left(E_{0}, \gamma\right)$ yield the single combination $E_{0}^{\mathrm{eq}}=0.108$ and $\gamma^{\mathrm{eq}}=0.887$. In the following we are interested in analyzing the implications of capital market driven changes in the risk-free interest rate $r_{\mathrm{f}}$ while all other parameters, and, in particular, the interest rate guarantee $g=1.75 \%$ remains unchanged. In general, an adjustment to the guaranteed interest rate will occur as a response to changes in capital market conditions. However, there is typically a time-lag for regulatory adjustments which can lead to the situations described in this section. In the following, we characterize the resulting parameter settings by the difference between the risk-free rate and the guaranteed interest rate, i.e., $r_{\mathrm{f}}-g$.

In Table 3 , we report the resulting equity capital - asset allocation equilibria $\left(E_{0}^{\mathrm{eq}}, \gamma^{\mathrm{eq}}\right)$ implied by the conditions (A) to (D) when varying the risk-free interest rate $r_{\mathrm{f}}$ between $4 \%$ and $2 \%$. Given a guaranteed interest rate of $g=1.75 \%$, the difference $r_{\mathrm{f}}-g$ varies between $2.25 \%$ and $0.25 \%$. The graph in Figure 3 gives a graphical illustration of the resulting combinations.

Variations of $r_{\mathrm{f}}$, while $g$ and $\alpha$ remain unchanged by the regulator, imply an adjustment by insurance 


\begin{tabular}{ccc|cc}
\hline \multicolumn{3}{c|}{ Interest rates (in \%) } & \multicolumn{2}{c}{ Insurer position } \\
$r_{\mathrm{f}}$ & $g$ & $r_{\mathrm{f}}-g$ & $E_{0}^{\mathrm{eq}}$ & $\gamma^{\mathrm{eq}}$ \\
\hline $\mathbf{4 . 0 0}$ & 1.75 & 2.25 & 0.185 & 0.817 \\
$\mathbf{3 . 7 5}$ & 1.75 & 2.00 & 0.165 & 0.834 \\
$\mathbf{3 . 5 0}$ & 1.75 & 1.75 & 0.146 & 0.851 \\
$\mathbf{3 . 2 5}$ & 1.75 & 1.50 & 0.128 & 0.869 \\
$\mathbf{3 . 0 0}$ & 1.75 & 1.25 & 0.108 & 0.887 \\
$\mathbf{2 . 7 5}$ & 1.75 & 1.00 & 0.090 & 0.905 \\
$\mathbf{2 . 5 0}$ & 1.75 & 0.75 & 0.072 & 0.924 \\
$\mathbf{2 . 2 5}$ & 1.75 & 0.50 & 0.055 & 0.943 \\
$\mathbf{2 . 0 0}$ & 1.75 & 0.25 & 0.038 & 0.963 \\
\hline
\end{tabular}

Table 3: Resulting combinations of equity capital $E_{0}^{\mathrm{eq}}$ and asset allocation $\gamma^{\mathrm{eq}}$ under variation of the risk-free interest rate $r_{\mathrm{f}}$ with fixed interest rate guarantee $g=1.75 \%$.

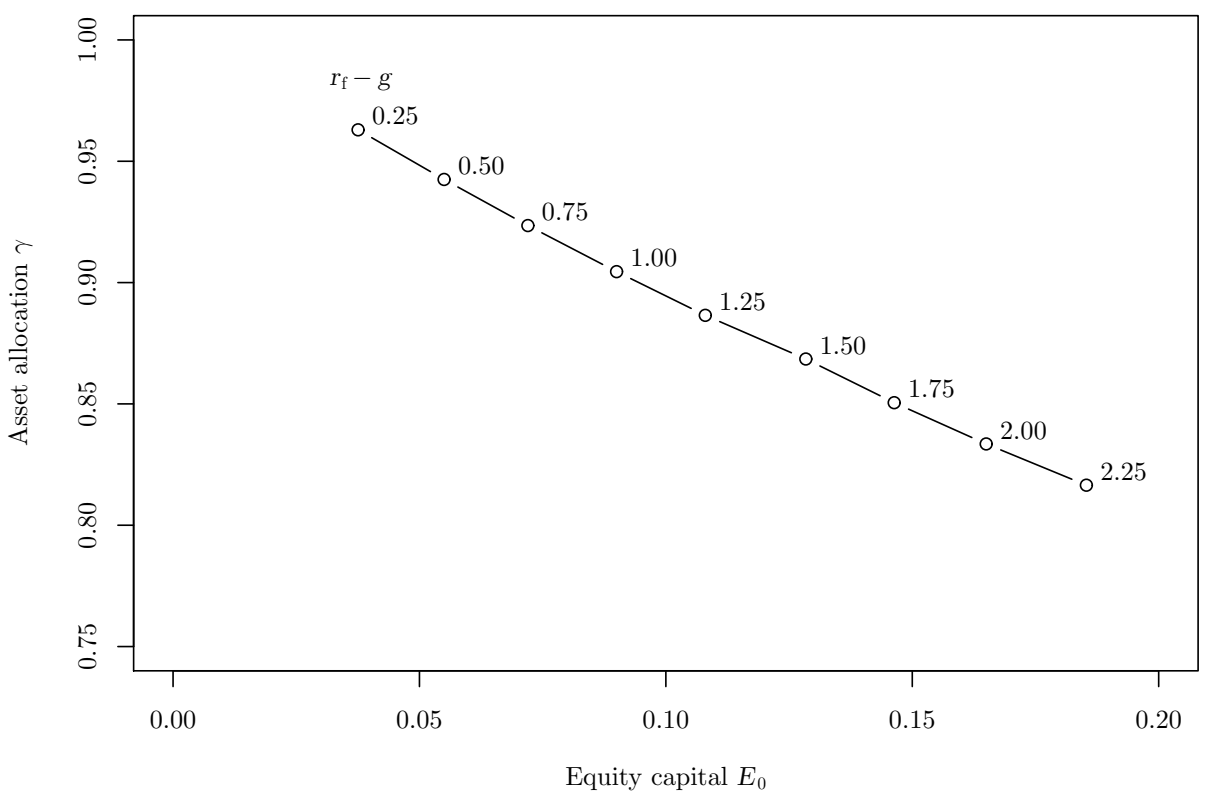

Figure 3: Illustration of the combinations of equity capital $E_{0}^{\mathrm{eq}}$ and asset allocation $\gamma^{\mathrm{eq}}$ under variation of the risk-free interest rate $r_{\mathrm{f}}$ between $2.0 \%$ and $4.0 \%$ with the interest rate guarantee $g=1.75 \%$ fixed. The labels of the data points reflect the respective value of $r_{\mathrm{f}}-g$.

companies of their equity capital and investment behavior. In order to comply with the solvency requirement (condition $\mathrm{C}$ ) and under the competitive market assumption (condition D), the amount of equity capital $E_{0}$ and the investment strategy (ratio of risk-free to risky assets) is adjusted. Numerical results (see Table 3 and Figure 3) show that the closer the risk-free rate $r_{\mathrm{f}}$ is to the guaranteed rate $g$, i.e., 
the smaller the difference $r_{\mathrm{f}}-g$, the more an insurance company tends to invest only in risk-free assets $\left(\gamma^{\mathrm{eq}}\right.$ closer to 1$)$ and is forced to reduce equity capital ( $E_{0}^{\mathrm{eq}}$ closer to 0$)$. Keeping $g$ unchanged while the risk-free return in capital markets declines can lead in extremis to situations where the insurance company is not investing in risky assets any more and is reducing its equity capital to zero.

In the following we discuss the implications of such a situation where $E_{0}^{\mathrm{eq}} \rightarrow 0$ and $\gamma^{\mathrm{eq}} \rightarrow 1$. When a life insurance contract mutates into a safe investment, the minimum interest rate and participation options become worthless. Especially with regard to the high transaction costs often found in insurance policies, the question arises whether customers would not be better off investing directly in the corresponding riskfree asset class. Furthermore, in such an extreme situation, it should be noted that there is no further upside potential for customers. Policyholders are deprived of the opportunity for higher earnings and payouts. In insurance practice, the possibility of a risk-free investment assumed in our model setup can be viewed critically given, e.g., the background of the current national financial crisis of different states in the European Union. Hence, a rather undiversified investment in government bonds is indeed highly sensitive to variations in interest rates and, in addition, may only be risk-free at first glance. Finally, if equity capital has to be reduced as is the case in this scenario, insurance companies will face the problem of residual costs. In actual fact, equity capital may not be reduced at short notice, and, the insurer will be forced to consider waiving adequate returns to its equity holders.

Note that higher values of the interest rate difference $r_{\mathrm{f}}-g$, i.e., a relatively high risk-free interest rate compared to a relatively lower guaranteed return, enables insurers to build up sound equity capital and to invest in risky assets (lower values for the asset allocation parameter $\gamma$ ). The influence of the interest rate difference $r_{\mathrm{f}}-g$ on the insurer's position is illustrated by the results in Table 3 and the graph in Figure 3. The higher the difference between the interest rates, the higher the equity capital at equilibrium and the lower the investment rate in the riskless asset class.

Finally, let us emphasize that such a combination $\left(E_{0}^{\mathrm{eq}}, \gamma^{\mathrm{eq}}\right)$ does not exist in all possible situations (for example, in the case where the guaranteed interest rate is lower than the risk-free interest rate, $g>r_{\mathrm{f}}$ no combinations that fulfill the set requirements can be found). In such a situation the net present value of policyholder claims' is strictly positive for policyholders which is incompatible with the competitive market condition (D). Such a setting would prevent equity holders from obtaining a risk-adequate return on their investment.

Before concluding this section, we report a numerical analysis of the case where the insurance company may not be able to adjust its equity capital and asset allocation in order to comply with the competitive market condition. Let us consider the initial parameterization and the values of $E_{0}=0.108$ and $\gamma=0.887$ fixed. Our aim is to show the resulting insurer disadvantage that arises when the risk-free interest rate declines while the guaranteed interest rate remains unchanged. Table 4 reports the insurance company's net present value for different values of the risk-free interest rate. This result is of particular relevance when discussing a market scenario with a declining risk-free interest rate and portfolios that include insurance contracts with much higher legacy guaranteed interest rates $g$.

For the interpretation of the net present values given in Table 4, we need to consider that the premium was set to $P_{0}=1$ currency unit. Hence, if the risk-free interest rate declines to $1 \%$ with all other factors 


\begin{tabular}{cc|c}
\hline $\begin{array}{c}r_{\mathrm{f}} \\
(\text { in } \%)\end{array}$ & $\begin{array}{c}g \\
\text { (in \%) }\end{array}$ & $\begin{array}{c}\text { Insurer net } \\
\text { present value }\end{array}$ \\
\hline $\mathbf{3 . 0 0}$ & 1.75 & 0.000 \\
$\mathbf{2 . 7 5}$ & 1.75 & -0.010 \\
$\mathbf{2 . 5 0}$ & 1.75 & -0.021 \\
$\mathbf{2 . 2 5}$ & 1.75 & -0.032 \\
$\mathbf{2 . 0 0}$ & 1.75 & -0.043 \\
$\mathbf{1 . 7 5}$ & 1.75 & -0.054 \\
$\mathbf{1 . 5 0}$ & 1.75 & -0.063 \\
$\mathbf{1 . 2 5}$ & 1.75 & -0.070 \\
$\mathbf{1 . 0 0}$ & 1.75 & -0.076 \\
\hline
\end{tabular}

Table 4: Resulting net present values for the insurance companies with a risk-free interest rate $r_{\mathrm{f}}$ between $3 \%$ and $1 \%$ when the interest rate guarantee $g=1.75 \%$ is unchanged and the equity and asset allocation are given $\left(E_{0}=0.108, \gamma=0.887\right)$.

remaining unchanged, the negative net present value for the equity holders yields around $7.6 \%$ of the insurance company's premium income.

\subsection{A proposal on how the value of the guaranteed interest rate should be set}

In the previous section, the focus of the analysis was on the further implications for the position of the insurance companies when the risk-free return changes. We concluded that the difference of the guaranteed interest rate to the risk-free interest rate has severe implications for insurance companies and in particular for their ability to determine the level of their equity capital or asset allocation. The aim of the following is to derive the level at which the regulator should set the value of the interest rate guarantee in order to maximize policyholders' utility. We explicitly consider policyholder utility, different levels of risk aversion, and study what the optimal level of the guaranteed interest rate $g$ would be from the policyholder viewpoint.

In Section 2.2 the power (isoelastic) utility function is introduced in Equation (14) and conversely the certainty equivalent $C E$ in Equation (15). We set the Arrow-Pratt constant coefficient of relative risk aversion alternatively to $\rho=2,5$ and 8 . This allows us to also discuss the results from the point of view of a customer with a very low degree of risk aversion $(\rho=2)$ and of customers with higher degrees of risk aversion $(\rho=5$ and $\rho=8)$.

We consider the previously used parameterization (see Table 1) and assume the risk-free interest rate $r_{\mathrm{f}}=3 \%$ as a given. We assume a guaranteed interest rate with values between $g=2.5 \%$ and $-10.0 \%$. In each setting we evaluate the insurer's position through the equilibrium values for $E_{0}$ and $\gamma$. These values are reported in the third and fourth columns in Table 5 similarly to the report in Table 3. Furthermore, we analyze the corresponding policyholder payoff distribution $L_{T}$ and give its characteristics, namely, the values of the expected value, the standard deviation and the skewness. Finally, we evaluate the certainty equivalent $C E$ for policyholders having different relative risk aversion coefficients $\rho=2,5$ and 8 . The 
respective values of $C E$ are reported in the last columns in Table $5 .^{9}$

\begin{tabular}{cc|cc|ccc|ccc}
\hline \multicolumn{2}{c|}{ Interest $($ in $\%)$} & \multicolumn{2}{|c|}{ Insurer } & \multicolumn{3}{c|}{ Characteristics of $L_{T}$} & \multicolumn{3}{c}{$C E$ of payoff $L_{T}$} \\
$r_{\mathrm{f}}$ & $g$ & $E_{0}^{\text {eq }}$ & $\gamma^{\text {eq }}$ & $E\left[L_{T}\right]$ & $\sigma\left[L_{T}\right]$ & $\mathrm{S}\left[L_{T}\right]$ & $\rho=2$ & $\rho=5$ & $\rho=8$ \\
\hline 3.0 & $\mathbf{2 . 5}$ & 0.07 & 0.93 & 1.37 & 0.04 & 0.45 & 1.370 & 1.369 & 1.367 \\
3.0 & $\mathbf{2 . 0}$ & 0.09 & 0.90 & 1.38 & 0.06 & 0.42 & 1.380 & 1.377 & 1.373 \\
3.0 & $\mathbf{1 . 5}$ & 0.12 & 0.87 & 1.39 & 0.08 & 0.44 & 1.389 & 1.383 & 1.376 \\
3.0 & $\mathbf{1 . 0}$ & 0.14 & 0.84 & 1.41 & 0.10 & 0.46 & 1.401 & 1.390 & $\mathbf{1 . 3 8 0}$ \\
3.0 & $\mathbf{0 . 5}$ & 0.16 & 0.82 & 1.42 & 0.12 & 0.49 & 1.408 & 1.393 & 1.379 \\
3.0 & $\mathbf{0 . 0}$ & 0.19 & 0.79 & 1.43 & 0.15 & 0.52 & 1.419 & 1.398 & 1.379 \\
3.0 & $\mathbf{- 0 . 5}$ & 0.21 & 0.76 & 1.44 & 0.17 & 0.55 & 1.426 & 1.400 & 1.375 \\
3.0 & $\mathbf{- 1 . 0}$ & 0.23 & 0.74 & 1.46 & 0.19 & 0.59 & 1.433 & $\mathbf{1 . 4 0 0}$ & 1.370 \\
3.0 & $\mathbf{- 1 . 5}$ & 0.25 & 0.71 & 1.47 & 0.21 & 0.61 & 1.439 & 1.400 & 1.362 \\
3.0 & $\mathbf{- 2 . 0}$ & 0.26 & 0.69 & 1.48 & 0.23 & 0.65 & 1.447 & 1.400 & 1.356 \\
3.0 & $\mathbf{- 2 . 5}$ & 0.29 & 0.66 & 1.49 & 0.25 & 0.71 & 1.454 & 1.397 & 1.347 \\
3.0 & $\mathbf{\ldots}$ & $\ldots$ & $\ldots$ & $\ldots$ & $\ldots$ & $\ldots$ & $\ldots$ & $\ldots$ & $\ldots$ \\
3.0 & $\mathbf{- 1 0 . 0}$ & 0.47 & 0.36 & 1.66 & 0.59 & 1.27 & $\mathbf{1 . 4 8 7}$ & 1.273 & 1.105 \\
\hline
\end{tabular}

Table 5: Resulting combinations of equity capital $E_{0}^{\mathrm{eq}}$ and asset allocation $\gamma^{\text {eq }}$ under variation of the guaranteed interest rate $g$ with fixed risk-free interest rate $r_{\mathrm{f}}=3 \%$. $E[\cdot]$ denotes the expected value (under $\mathbb{P}), \sigma[\cdot]$ the standard deviation and $S[\cdot]$ the skewness. $C E$ stands for the certainty equivalent. Its maximum value in each $\rho$-case is printed in bold.

Considering the reported results in Table 5, and in-line with our findings in Section 3.2, we conclude that the higher the offered guaranteed return $g$ (for the given risk-free return), the higher the investment in the risk-free asset class and the lower the equity capital underpinning. Expressed the other way round: for lower values of $g$, the insurer invests more riskily but also enhances its equity capital base. With declining values of $g$, we conclude from the results that the expected value, the standard deviation and the skewness of the payoff increase. This has implications for the policyholder's expected utility or certainty equivalent (see also the illustration in Figure 4). In fact, the certainty equivalent, and hence the expected policyholder utility, yields higher values the lower the guaranteed interest rate (and the more volatile the insurer's asset allocation) - up to a certain threshold. In the case of an individual with a low risk aversion, the certainty equivalent $C E$ reaches its maximum for $g=-10.0 \%$, while for risk-averse customers with $\rho=5$, the optimal contract offers a guaranteed interest rate of $g=-1.0 \%$ (respectively $g=1.0 \%$ when $\rho=8$ ).

In view of these findings, we conclude that the regulator's setting a lower value for the upper bound of the interest rate guarantee may be beneficial to the final policyholder payoff structure and individual utility. In fact, depending on the considered level of individual risk aversion, and in the considered reference setting, the optimal value for the interest rate guarantee $g$ may yield values which are strictly below $g=1 \%$. However, this range is the opposite of the one that could be obtained when applying an

\footnotetext{
${ }^{9}$ Note that the reported values for the $C E$ are all higher than the corresponding certainty equivalents which could be obtained if the policyholder invests $P_{0}$ directly into the two available asset classes (risk-free at $r_{\mathrm{f}}=3.0 \%$ and risky at $\left.\left(\mu_{\mathrm{GBM}}, \sigma_{\mathrm{GBM}}\right)=(7.0 \%, 20.0 \%)\right)$ with an asset allocation given by $\gamma^{\text {eq }}$. For example, where $\gamma^{\text {eq }}=0.93$ and risk aversion $\rho=8$, investing $P_{0}=1$ throughout the duration $T$ in the capital market yields a certainty equivalent of 1.359 while the $C E$ of the insurance policy is 1.367 (see Table 3). Similarly, where $\gamma^{\text {eq }}=0.36$, we obtain a certainty equivalent of 0.864 while the insurance contract yields $C E=1.105$.
} 
intuitive analysis wherein higher values of $g$ should be superior (also see the discussion in Section 2.2) nor does it reflect current practice to offer the highest possible interest rate guarantee given the known potential effects on the insurer's asset allocation (compare also Section 3.2). Particularly in market conditions where the risk-free interest rate decreases, adapting $g$ to an adequately low value may increase the benefits of policyholders, even highly risk-averse ones.

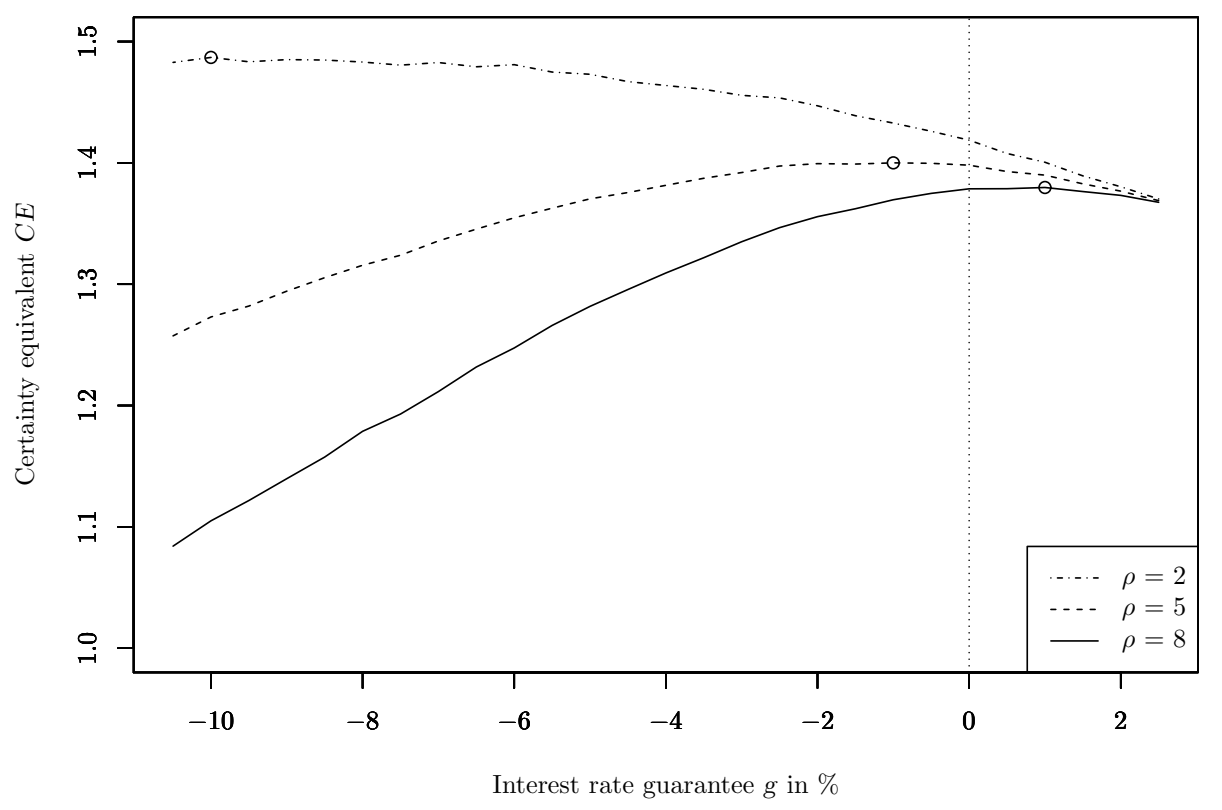

Figure 4: Illustration of the certainty equivalent $C E$ for different values of the guaranteed interest rate $g$ for fixed $r_{\mathrm{f}}=3 \%$. The three depicted curves report the values for different values of the coefficient of relative risk aversion $\rho$ corresponding to preferences with a low degree of risk aversion $(\rho=2)$ up to higher degrees of risk aversion ( $\rho=5$ and 8 ). The circle on each curve reflects the position where the $C E$ is maximum.

Before concluding this section, we compare the payoff from the life insurance product considered throughout this paper with three different investments (see summary of our results in Table 6) in order to derive a comparison of the utility of alternative products. For this, we consider an upfront investment of $P_{0}=1$ for a duration of $T=10$ years. First we recapitulate the results of the payoff from a participating life insurance policy (product (a)) with a guaranteed annual interest rate of $g=1 \%$ and the insurer's underlying positioning with $\gamma=0.84$ and $E_{0}=0.14$ (fair value ensuring the interest rate guarantee) as reported in Table 5. Next we consider an investment of $P_{0}$ into three different products. For this we consider a mixed investment (product (b)) maintaining the same asset allocation than in product (a) with $\gamma=0.84$. This means that $84 \%$ of $P_{0}$ are invested risk-free and the remaining $16 \%$ are invested into stocks. In products (c) and (d) the asset allocation corresponds to a pure stocks investement $(\gamma=0.00)$ 
respectively a $100 \%(\gamma=1.00)$ investment in risk-free assets.

Table 6 reports the payout for the selected products and investments. Besides the expected value, the standard deviation and skewness of the payout at the investment term, the certainty equivalent $C E$ for different degrees of risk aversion is given. The results show that for different risk-averse policyholders the insurance product with its annual interest rate guarantee yields the highest values for the $C E$. The more risk-averse the policyholders (higher values of $\rho$ ), the more the insurance product becomes attractive.

\begin{tabular}{ll|c|ccc|cccc}
\hline \multirow{2}{*}{ Product / Investment } & Asset all. & \multicolumn{3}{|c|}{ Payout } & \multicolumn{4}{|c}{$C E$ of payout } \\
& & $\gamma$ & $E[\cdot]$ & $\sigma[\cdot]$ & $\mathrm{S}[\cdot]$ & $\rho=2$ & $\rho=5$ & $\rho=8$ \\
\hline (a) & Insurance, $g=1.0 \%, E_{0}=0.14$ & 0.84 & 1.41 & 0.10 & 0.46 & 1.401 & 1.390 & 1.380 \\
(b) & Mixed investment, no guarantee & 0.84 & 1.40 & 0.14 & 0.31 & 1.387 & 1.366 & 1.345 \\
(c) & Stocks investment, no guarantee & 0.00 & 2.03 & 1.44 & 2.55 & 1.354 & 0.731 & 0.382 \\
(d) & Risk-free investm., no guarantee & 1.00 & 1.35 & 0.00 & - & 1.350 & 1.350 & 1.350 \\
\hline
\end{tabular}

Table 6: Characterization of the resulting payouts from selected financial products for an upfront investment of $P_{0}=1$. Product (a) is a life insurance policy with guaranteed interest rate $g=1 \%$ and policyholder participation $\alpha=90 \%$ (compare with Table 5). Products (b) to (d) are investments in assets without any guarantee. In the latter the upfront payment is invested along the asset allocation given by $\gamma$. The risk-free interest rate is kept at $r_{\mathrm{f}}=3 \%$ and the investment term at $T=10$ years. The capital market conditions are taken from the parameterization given in Table 1. $E[\cdot]$ denotes the expected value (under $\mathbb{P}), \sigma[\cdot]$ the standard deviation and $S[\cdot]$ the skewness. The certainty equivalent $C E$ is given for policyholders with different risk aversion parameters $\rho$.

Recall that the net present value is identical in all products (a) to (d) and equal to zero. Hence the insurance product and all alternatives yield risk-adequate returns. Product (a) is subject to default risk and investment risk. The guarantee is supported up to a safety level of $1-\epsilon$ (ruin probability $\epsilon$ ) through the insurer's equity capital $E_{0}$. Products (b) and (c) bear pure investment risk while product (d) is risk-free. Among the four alternatives considered here, product (a) yields the highest policyholder utility. However, it is not necessarily the "best" possible product for the $\rho$-values considered. Note that if the policyholders are risk-neutral $(\rho=0)$, the $C E$ corresponds to the expected value of the payout, in which case the investment of type (c) would be preferable.

\subsection{Illustration of the stability of the results}

The aim of this section is to give an overview of some additional sensitivity analyses. This study shows that the obtained results are stable with respect to selected changes in the parameterization. On the one hand, we analyze the influence of the contract length $T$ on the insurer's equity capital and asset allocation, on the other hand, we assess the relevance of the safety requirement $\epsilon$. The respective results are reported in Table 7. In addition to the insurer's position we show that the contract length $T$ has no significant influence to what level the guaranteed interest rate should be set (see Table 8).

Influence of the safety level $\epsilon$ : Table 7(a) summarizes the resulting implications for the insurer's position and policyholder utility when the safety requirement $\epsilon$ is changed and all other parameters remain unchanged. While throughout our previous analysis, we used the value $\epsilon=0.5 \%$ as a reference 
safety level (see Table 1), Table 7 (a) reports the implications for $\epsilon=10.0 \%$ through $\epsilon=0.1 \%$. In fact a $T$-year safety requirement for a given level of $\epsilon$ is stricter than a year-to-year requirement at the same level. Thus we also consider higher values of $\epsilon$ (than the one considered in the Solvency II framework). We conclude that changes in the parameter $\epsilon$ are correlated to the level of equity capital $E_{0}^{\text {eq }}$, whereas the asset allocation $\gamma^{\text {eq }}$ is mostly unaffected. This can also be put into the context of our results in Section 3.1. From the graph in Figure 2 we can conclude that the asset allocation $\gamma$ is stable for a broad range of situations on the competitive market condition curve (the curve is flat for a large range of equity levels). In fact, requiring a safety level of $\epsilon=0.1 \%$ leads to an equilibrium position with slightly higher equity capital than with $\epsilon=0.5 \%$ (0.120 versus 0.108 C.U.). Hence the intersection point in Figure 2 of the curve representing the competitive market condition (solid curve) and the safety condition (with $\epsilon=0.1 \%$ ) moves to the right. Finally, and similarly to the asset allocation, we conclude from the results that the certainty equivalent is not influenced by the value of the safety level in this model.

Influence of the contract length $T$ : The results reported in Table $7(\mathrm{~b})$ show the effects of different contract durations $T$ on the insurer's position. Clearly, the contract length has an impact on the amount of equity capital (since guarantees to policyholders increase with time). The necessary equity capital $E_{0}^{\text {eq }}$ is positively correlated with the contract duration. However the asset allocation $\gamma^{\text {eq }}$ is unaffected by the contract length in the present model framework.

(a) Variation of the safety requirement $\epsilon$

\begin{tabular}{c|cc|cc}
\hline$\epsilon$ & $E_{0}^{\mathrm{eq}}$ & $\gamma^{\mathrm{eq}}$ & $\begin{array}{l}C E \\
\rho=2\end{array}$ & $\begin{array}{l}C E \\
\rho=8\end{array}$ \\
\hline $10.0 \%$ & 0.059 & 0.876 & 1.392 & 1.379 \\
$5.0 \%$ & 0.069 & 0.882 & 1.389 & 1.378 \\
$1.0 \%$ & 0.096 & 0.886 & 1.386 & 1.376 \\
$0.5 \%$ & 0.108 & 0.887 & 1.386 & 1.375 \\
$0.1 \%$ & 0.120 & 0.887 & 1.385 & 1.375 \\
\hline
\end{tabular}

(b) Variation of contract length $T$

\begin{tabular}{c|cc}
\hline$T$ & $E_{0}^{\mathrm{eq}}$ & $\gamma^{\mathrm{eq}}$ \\
\hline (years) & & \\
\hline 1 & 0.039 & 0.885 \\
2 & 0.056 & 0.886 \\
5 & 0.071 & 0.886 \\
10 & 0.108 & 0.887 \\
20 & 0.152 & 0.887 \\
30 & 0.186 & 0.887 \\
\hline
\end{tabular}

Table 7: Resulting combinations of equity capital $E_{0}^{\mathrm{eq}}$, asset allocation $\gamma^{\mathrm{eq}}$ and certainty equivalent $C E$ for two values of the risk aversion parameter $(\rho=2$ and $\rho=8)$ under variation of the safety requirement $\epsilon$ and the contract length $T$. The basis of the sensitivity analysis is the parameterization of the reference setting (see Table 1).

In addition, and similarly to Table 5 in Section 3.3, the numerical report in Table 8 illustrates the evolution of the certainty equivalent $C E$ of the policyholder payoff $L_{T}$ with respect to different values of the guaranteed interest rate for two settings of the customer degree of risk aversion $(\rho=5$ and $\rho=8$ ) and different contract lengths $(T=5,10,20)$. Results show that the level of guaranteed interest rate $g$ which maximizes the policyholder certainty equivalent is stable when considering contracts of different durations. In the case with a degree of risk aversion $\rho=8$ the optimal value for $g$ yields around $1.0 \%$ for the three contract lengths considered. If the risk aversion parameter is $\rho=5$ the guaranteed interest rate $g$ should be set to $-1.0 \%$ in our parameterization. Hence, in the case the regulator adopts the provided concept of deriving an optimal value for the minimum interest rate guarantee for policyholders with a 
given value of $\rho$, one single value for $g$ could be chosen independently of the contract's duration.

\begin{tabular}{|c|c|c|c|c|c|c|c|}
\hline & & \multicolumn{6}{|c|}{$C E$ of payoff $L_{T}$} \\
\hline \multicolumn{2}{|c|}{ Interest (in \%) } & & $\rho=5$ & & & $\rho=8$ & \\
\hline$r_{\mathrm{f}}$ & $g$ & $T=5$ & $T=10$ & $T=20$ & $T=5$ & $T=10$ & $T=20$ \\
\hline 3.0 & 2.5 & 1.170 & 1.369 & 1.874 & 1.169 & 1.367 & 1.870 \\
\hline 3.0 & 2.0 & 1.173 & 1.377 & 1.899 & 1.171 & 1.373 & 1.889 \\
\hline 3.0 & 1.5 & 1.176 & 1.383 & 1.912 & 1.173 & 1.376 & 1.894 \\
\hline 3.0 & 1.0 & 1.179 & 1.390 & 1.933 & 1.175 & 1.380 & 1.905 \\
\hline 3.0 & 0.5 & 1.182 & 1.393 & 1.940 & 1.175 & 1.379 & 1.901 \\
\hline 3.0 & 0.0 & 1.182 & 1.398 & 1.955 & 1.174 & 1.379 & 1.900 \\
\hline 3.0 & -0.5 & 1.183 & 1.400 & 1.958 & 1.172 & 1.375 & 1.890 \\
\hline 3.0 & -1.0 & 1.183 & 1.400 & 1.959 & 1.170 & 1.370 & 1.874 \\
\hline 3.0 & -1.5 & 1.183 & 1.400 & 1.959 & 1.167 & 1.362 & 1.857 \\
\hline 3.0 & -2.0 & 1.182 & 1.400 & 1.955 & 1.164 & 1.356 & 1.835 \\
\hline 3.0 & -2.5 & 1.180 & 1.397 & 1.942 & 1.159 & 1.347 & 1.802 \\
\hline
\end{tabular}

Table 8: Resulting values of the policyholder certainty equivalent $C E$ under variation of the guaranteed interest rate $g$ between $2.5 \%$ and $-2.5 \%$ with fixed risk-free interest rate $r_{\mathrm{f}}=3 \%$ for two values of the risk aversion parameter $(\rho=5$ and $\rho=8)$ and three values of the contract length $(T=5,10$, $20)$. The maximum value of $C E$ in each $(\rho, T)$-case is printed in bold. The basis of the analysis is the parameterization of the reference setting (see Table 1).

Thus, our discussion of the effects on the insurers position and its product offering in particular hold. Since in the considered range of values the safety level does not change policyholder utility, the optimal value of the guaranteed interest rate $g$ is stable. Furthermore, the contract duration does not considerably influence the optimal value of the guaranteed interest rate $g$.

\section{Conclusion}

This work analyzes the interactions of interest rate guarantees on the equity capital and asset allocation of an insurance company offering traditional participating life insurance contracts. Furthermore we consider the question of which maximum value the regulator should set for the guaranteed interest rate in favor of the policyholders. In this context, a contingent claim model framework in a competitive market is used that integrates the positions of the equity holders and policyholders. The model assumes that the maximum value of the interest guarantee and the minimum value of the policyholder participation are adjusted precisely adopted by the insurer. Furthermore a solvency requirement limiting the contract default probability is integrated in the model setup.

In the first part, the interaction between interest rates and the insurance company's position is analyzed. The study finds that, for given interest rates and under the model assumptions, the resulting equity capital and investment strategy of the insurer are fully and simultaneously determined.

Second, capital market changes with a variation of the risk-free interest rate versus the interest rate guarantee imply that the insurer's asset allocation tends to be quasi riskless and equity capital is 
necessarily (almost) zero. This has severe consequences for the value of the contract and the options offered to customers as well as on the concept of this type of insurance per se. Furthermore we calculate the residual costs borne by an insurance company that cannot reduce its equity capital at short notice.

Finally, an assessment of the individual expected utility of risk-averse customers concludes that the regulator, by setting a lower (maximum) interest rate guarantee can achieve higher contract utility for the customer. The optimal level of the interest rate guarantee depends on the individual preferences considered. However, our results give a solid indication of how the regulator and insurers should adjust the product regulation and product offering respectively. In addition, we show that the results yielded by the proposed concept to derive an optimal value for the interest rate guarantee are very stable for various model parameters.

\section{References}

Bacinello, A., 2003, Fair Valuation of a Guaranteed Life Insurance Participating Contract Embedding a Surrender Option, The Journal of Risk and Insurance, 70(3):461-487.

Ballotta, L. and S. Haberman, 2003, Valuation of Guaranteed Annuity Conversion Options, Insurance: Mathematics and Economics, 33(1):87-108.

Ballotta, L., S. Haberman, and N. Wang, 2003, Modelling and Valuation of Guarantees in With-Profit and Unitised With Profit Life Insurance Contracts, Working Paper, (available on SSRN).

Ballotta, L., S. Haberman, and N. Wang, 2006, Guarantees in With-Profit and Unitized With-Profit Life Insurance Contracts: Fair Valuation Problem in Presence of the Default Option, The Journal of Risk and Insurance, 73(1):97-121.

Berketi, A. K., 1999, Insolvency Risk and its Impact on the Policyholders Investment Choices: A MeanVariance Approach for Participating Life Insurance Business in UK, Insurance: Mathematics and Economics, 25(3):349-372.

Björk, T., 2004, Arbitrage Theory in Continuous Time. Oxford University Press, New York.

Bohnert, A. and N. Gatzert, 2012, Analyzing Surplus Appropriation Schemes in Participating Life Insurance from the Insurers and the Policyholders Perspective, Insurance: Mathematics and Economics, 50(1):64-78.

Briys, E. and F. de Varenne, 1997, On the Risk of Insurance Liabilities: Debunking Some Common Pitfalls, The Journal of Risk and Insurance, 64(4):673-694.

Broeders, D., A. Chen, and B. Koos, 2011, A Utility-Based Comparison of Pension Funds and Life Insurance Companies under Regulatory Constraints, Insurance: Mathematics and Economics, 49(1):110 .

Butsic, R. P., 1994, Solvency Measurement for Property-Liability Risk-Based Capital Applications, The Journal of Risk and Insurance, 61(4):656-690. 
Cummins, J. D., K. R. Miltersen, and S.-A. Persson, 2007, International Comparison of Interest Rate Guarantees in Life Insurance Contracts, Working Paper, (available on SSRN).

Doherty, N. and J. Garven, 1986, Price Regulation in Property-Liability Insurance: A Contingent-Claims Approach, Journal of Finance, 41(5):1031-1050.

Eling, M. and S. Holder, 2012, Maximum Technical Interest Rates in Life Insurance in Europe and the United States: An Overview and Comparison, The Geneva Papers on Risk and Insurance - Issues and Practice, (forthcoming).

Eling, M., H. Schmeiser, and J. T. Schmit, 2007, The Solvency II Process: Overview and Critial Analysis, Risk Management 83 Insurance Review, 10(1):69-85.

European Commission, 2010, QIS5 Technical Specifications, July.

European Union, 1992, Council Directive 92/96/EEC of the European Parliament and of the Council, Official Journal of European Communities.

European Union, 2002, Directive 2002/13/EC of the European Parliament and of the Council, Official Journal of European Communities.

European Union, 2009, Directive 2009/138/EC of the European Parliament and of the Council, Official Journal of the European Union, (25 November).

Fromme, H., 2011, Lebenslänglich wird Auslaufmodell, Financial Times Deutschland, (23 December).

Gatzert, N., 2008, Asset Management and Surplus Distribution Strategies in Life Insurance: An Examination with Respect to Risk Pricing and Risk Measurement, Insurance: Mathematics and Economics, $42(2): 839-849$.

Gatzert, N., I. Holzmüller, and H. Schmeiser, 2012, Creating Customer Value in Participating Life Insurance, The Journal of Risk and Insurance, 79(3):645-670.

Gatzert, N. and A. Kling, 2007, Analysis of Participating Life Insurance Contracts: A Unification Approach, The Journal of Risk and Insurance, 74(3):547-570.

German Federal Ministry of Justice, 2008, Verordnung über die Mindestbeitragsrückerstattung in der Lebensversicherung (MindZV).

German Federal Ministry of Justice, 2011, Verordnung über Rechnungsgrundlagen für die Deckungsrückstellungen (DeckRV).

Gesamtverband der Deutschen Versicherungswirtschaft e.V. (GDV), 2012, Statistisches Taschenbuch der Versicherungswirtschaft 2012.

Grosen, A. and P. Jorgensen, 2000, Fair Valuation of Life Insurance Liabilities: The Impact of Interest Rate Guarantees, Surrender Options, and Bonus Policies, Insurance: Mathematics and Economics, 26(1):37-57. 
Grosen, A. and P. Jorgensen, 2002, Life Insurance Liabilities at Market Value: An Analysis of Insolvency Risk, Bonus Policy, and Regulatory Intervention Rules in a Barrier Option Framework, The Journal of Risk and Insurance, 69(1):63-91.

Gründl, H. and H. Schmeiser, 2007, Capital Allocation for Insurance Companies - What Good Is It?, The Journal of Risk and Insurance, 74(2):301-317.

Heinen, N., 2011, Lebensversicherungen zwischen Baum und Borke, Versicherungswirtschaft, 66(5):318319 .

Klein, A. M. and V. Butala, 2004, The Challenge of Lower Interest Rates on Universal Life Insurance, Contingencies, (January/February):22-26.

Kling, A., A. Richter, and J. Ruß, 2007a, The Impact of Surplus Distribution on the Risk Exposure of With Profit Life Insurance Policies Including Interest Rate Guarantees, The Journal of Risk and Insurance, 74(3):571-589.

Kling, A., A. Richter, and J. Ruß, 2007b, The Interaction of Guarantees, Surplus Distribution, and Asset Allocation in With-Profit Life Insurance Policies, Insurance: Mathematics and Economics, 40(1):164178 .

Merton, R. C., 1969, Lifetime Portfolio Selection under Uncertainty: The Continuous-Time Case, The Review of Economics and Statistics, 51(3):247-257.

Myers, S. C. and J. A. Read Jr., 2001, Capital Allocation for Insurance Companies, The Journal of Risk and Insurance, 68(4):545-580.

Phillips, R. D., J. D. Cummins, and F. Allen, 1998, Financial Pricing of Insurance in the Multiple-Line Insurance Company, The Journal of Risk and Insurance, 65(4):597-636.

Schmeiser, H. and J. Wagner, 2011, A Joint Valuation of Premium Payment and Surrender Options In Participating Life Insurance Contracts, Insurance: Mathematics and Economics, 49(3):580-596.

Schmeiser, H. and J. Wagner, 2012, The Impact of Introducing Insurance Guaranty Schemes on Pricing and Capital Structure, The Journal of Risk and Insurance, (forthcoming).

Wright, K. M., 1991, The Structure, Conduct, and Regulation of the Life Insurance Industry, In R. Kopcke and R. Randall, editors, The Financial Condition of Insurance Companies, pages 73-96. Federal Reserve Bank Boston, Boston. 